Ethiopian Journal of Environmental Studies \& Management 9 (2): 245 - 254, 2016.

ISSN:1998-0507

doi:http://dx.doi.org/10.4314/ejesm.v9i2.12

Submitted: December 22, 2015

Accepted: April 14, 2016

\title{
THE IMPACT OF COMMUNITY PARTICIPATION IN RURAL WATER MANAGEMENT IN NDARUGU-THIRIRIKA SUB-CATCHMENT, ATHI BASIN, KENYA
}

*WAITHAKA, A., KISOVI, L.M. AND OBANDO, J.

Department of Geography, Kenyatta University, P.O. Box 43844-00100, Nairobi, Kenya

\begin{abstract}
In rural areas, water availability in the right quantity and quality is an important step towards achieving socio-economic development. Thus, the provision of sustainable water supply has been a central issue in Kenya with priority on low-income rural communities and underdeveloped areas with poor water resources. This has forced many rural communities to embrace community management model in rural water systems. Community participation in rural water management is purportedly a key element for community water projects to be sustainable. The objective of this paper was to assess the impact of community participation in rural water management in four community-managed rural water supply projects, namely Kinyathena, Juja Farm, Munyu and Kamunyaka. Different types of data were collected using household questionnaires, in-depth interviews, Focus Group Discussions (FGDs) and Participatory Rural Appraisal (PRA). The data type collected included the socio-economic characteristics of the sample households and level of community participation. . The collected data was organized in Statistical Package for Social Sciences (SPSS) version 17.0 and Microsoft Excel. Descriptive statistics, frequencies and percentages were used to describe and summarize the data while inferential statistics, chi-square and ANOVA were used to reach conclusions and make generalizations of the population. Results indicate that $56.5 \%$ of the respondents agreed that community participation in rural water management has improved their livelihoods. Therefore the study concludes that community participation in the subcatchment has impacted on the local community livelihoods by providing constant access to adequate water for domestic, agricultural uses, construction, reducing time wastage, general development and catchment management.
\end{abstract}

Key Words: Ndarugu-Thiririka sub-catchment, water management, Community participation

\section{Introduction}

The United Nations Millennium Declaration, 2000, set a target to halve the percentage of world's population without access to sustainable safe drinking water by 2015 . This facilitated the drive towards full global coverage by 2025 as in the Global Water Partnership Framework for

*Corresponding Author: Waithaka, A.

Email: ann.waithaka@yahoo.com
Action and the African Water Vision (ADB, 2007) and in the Kenya Vision 2030 which aims to ensure water availability and access to all by 2030 . About 2.8 billion people (more than $40 \%$ ) of the world population live in river basins faced with some form of water scarcity and 1.6 billion people live in areas of economic 
water scarcity, where even though water is available, human, institutional and financial capital limit access to water (UN, 2008).

The inability of governments to provide water supply services due to resource constraints has led to the widespread adoption of community managed rural water supply projects since the early 1980's (WHO,1996; World Bank, 2003; Harvey and Reed, 2007). There has also been a paradigm shift from top-bottom to bottom-up approach in development which recognizes the benefits of engaging the community and allows for local participation in decision making which has been welcomed even in rural water supply (IRC, 2003; Garande and Dagg 2005). Participatory approaches have gained substantial support in the international community (World Bank, 2003) with several international declarations including the Dublin Statement (1992), the Hague Declaration (2000) and the 2003 Water Forum in Kyoto promoting active public participation in decision making in water management.

Community participation is seen as a means to achieve a particular end as it enables communities to better manage their socio-economic environment, to help improve food security, to improve access to basic social services or to reverse the process of natural resource degradation with the ultimate goal of reducing rural poverty and promoting sustainable development (World Bank, 2003). Chambers (2007) also notes that a sharp reduction of poverty can be achieved when powerful professionals become participatory and get closer to and learn more from those living in resource poor environment.
Participation at the community level has been identified as one of the most essential principles in rural development projects, as it has the potential to give communities access and control over their water resources (OECD, 1985). UN (2003) also identified participation as a criterion for effective governance where all citizens, both men and women, should have a voice, directly or through intermediary organizations representing their interests, throughout the processes of policy and decision making.

The Water Act 2002 holds that one way of promoting an effective catchment management strategy is for Water Resources Management Authority (WRMA) to provide mechanisms and facilities for enabling the public and communities to participate in managing water resources. The underlying expectation in the use of community participation is that, putting communities in charge or actively engaging them in their own development will harness their social capital to improve livelihoods leading to sustainable development (World Bank, 2003). An empowered community is more likely to be pro-active and develop the confidence that would allow them to tackle other issues even beyond the projects' set objects (Garande and Dagg, 2005). Njogu (2009) in a study on challenges and opportunities for sustainable water supply and demand management in Ruiru Municipality recommends that various institutions mandated with policy formulation should adopt bottom-up decision making process by embracing public participation in planning issues.

This study therefore intended to assess the impact of community participation in rural water management in community- 
managed rural water supply projects. Community participation in rural water management is a necessary instrument in the attempt to alleviate poverty associated with inadequate water for basic purposes. The move towards effective community participation has also encouraged a shift from the traditional top-down to bottom-up approach which empowers a community.

\section{Methodology}

\section{The Study Area}

Ndarugu-Thiririka Sub-catchment cuts across three administrative districts: Gatundu, Thika West and Thika East Districts (Figure 1). It covers an area of $1218.5 \mathrm{~km}^{2}$ with a population of 510,408 people, an estimated average density of
435 people per square kilometer and 148,208 households (KNBS, 2009). It is a section of the upper and middle zones of the Athi Catchment. Its altitude ranges from $2600-1500 \mathrm{~m}$ mean above sea level in the upper zone and $1500-560 \mathrm{~m}$ mean above sea level across the middle zone. The climate varies across the subcatchment, typically being sub-humid in the upper region and semi-arid in the middle region. The sub-catchment has two distinct rainy seasons; long rains in MarchApril-May and short rains in OctoberNovember. Land use patterns are highly influenced by rainfall patterns, topography and human activity. Economically, the sub-catchment drains in a highly agricultural and industrialized area.

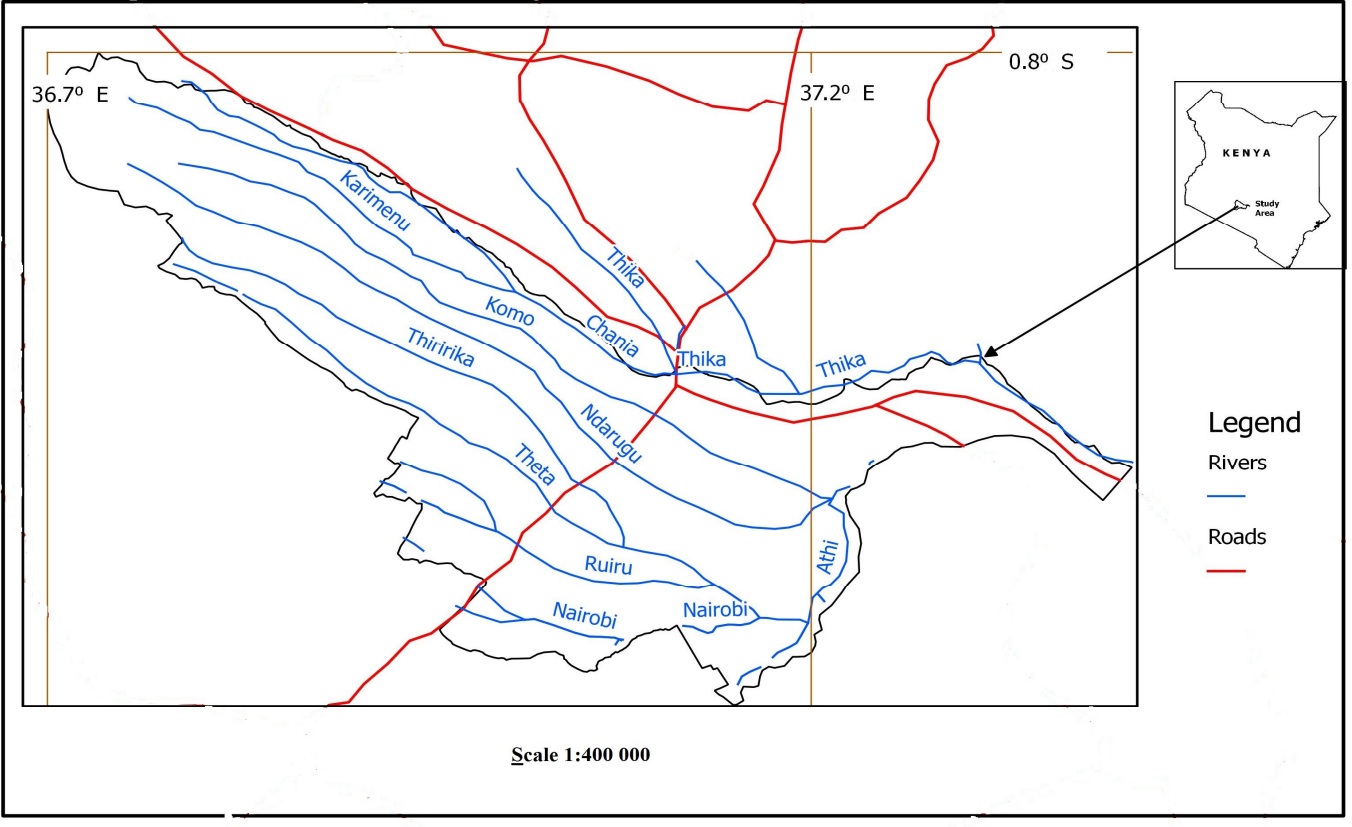

Figure 1 Ndarugu-Thiririka Sub-catchment

\section{Research Design}

A research design is the conceptual structure within which the research is conducted and constitutes the blue print for the collection measurement and analysis of data (Kothari, 2004). This study used a case study design to describe Ndarugu-
Thiririka sub-catchment and each selected community water project as a unit in details, context and holistically.

\section{Sample Design}

This study made use of both probability and non-probability sampling designs. In probability sampling design, 
each unit in the population had an equal chance of being selected while in nonprobability sampling design, the interest was in the representativeness of concepts in their varying form. Probability sampling designs such as cluster and random sampling designs were used while nonprobability sampling designs included purposive and free sampling designs. Specifically, cluster sampling was used because of the vastness of the study area. The study area was sub-divided into three geographical clusters which consisted of the administrative districts in the subcatchment with community water projects. Purposive sampling was used to select community water projects with the required characteristics in each district, households to be interviewed and also to get people with the required information on community participation in rural water management and its impacts.

Simple random sampling was carried out in the selected projects. The sampling frame consisted of the individuals who are beneficiaries of the selected community managed water projects. The households were identified from the community projects office records or the water committee chairpersons. Using the records, the households were listed in a numerical form to establish the actual number of households in each community water project. Random numbers were used to get the desired sample size. The sample size consisted of 200 households purposively selected out of the total 148,208 households in the sub-catchment. The heads of the households listed were interviewed. In case of their absence, the person available at the homestead was interviewed provided he/she was an adult of sound mind and above eighteen years.
Free sampling, where the units of observation are selected as they become available to the researcher, was used. This is because the area is characterized by a high population and also the fact that, it was not guaranteed to get every member of the selected sample due to their busy daily socio-economic activities.

\section{Target Population, Sample Size and Sample Frame}

The target population composed of residents in three districts; Gatundu, Thika West and Thika East in Kiambu County, who are served by the selected community water projects. The sampling frame consisted of individuals who are beneficiaries of the selected community managed water projects, water committee officials and resource persons from the Ministry of Water and Irrigation. In order to get a representative sample, a sample size of 200 households was purposively selected from the total 148,208 households in the sub-catchment. The selected households were apportioned according to the proportion of households in the three districts according to 2009 Kenya national population census (KNBS, 2009) (Table 1) using the equation;

$N=\frac{d}{T} \times 200$

(Equation 1)

Where

$N$ is the required household sample size in each district

$\boldsymbol{d}$ is the total number of households in each district in the sub-catchment

$\boldsymbol{T}$ is the total number of households in the sub-catchment, which is 148,208 households. 
Table 1 Sample size tabulation per district

\begin{tabular}{llll}
\hline District & Households & Community project & Sample size \\
\hline Thika East & 20,441 & Munyu & 28 \\
Gatundu & 55,716 & Kamunyaka & 75 \\
Thika West & 72,051 & Kinyathena & 49 \\
& & Juja-Farm & 48 \\
TOTAL & 148,208 & & 200 \\
\hline
\end{tabular}

\section{Data Types and Sources}

The study used both primary and secondary (documentary) sources of data. Primary data included household size, level of education, income, occupation, amount of money paid as water bills in Kenya Shillings and frequency of attending water project meetings of the sample households. They were collected by use of questionnaires, in-depth interviews, Focus Group Discussions (FGDs) and Participatory Rural Appraisal (PRA). Secondary data included documented donor and community resources. They also consisted of government policy papers relevant to the study which were collected and reviewed. The study also made use of secondary data from institutional libraries and published and unpublished research reports and journals.

\section{Data Collection, Processing and Analysis}

Data collection activities were followed directly from the objectives of the study. Household questionnaires, key informant interview guide and Focus Group Discussions guide were used. Household questionnaires consisted of both open-ended and close-ended questions. Key informant interviews were carried out to one water committee official in each community water project so as to collect comprehensive, systematic and indepth information on the impacts of community participation in rural water management. Five focus group discussions were conducted in order to get more clarification on community participation in the sub-catchment. Each focus group consisted of 8-10 members with gender and age considerations.

The collected field data was analyzed both quantitatively and qualitatively. The data was coded, classified and analyzed using Statistical Package for Social Sciences (SPSS) version 17.0. Descriptive statistics, frequencies and percentages were used to describe and summarize the data. Inferential statistics such as chisquare and ANOVA were used to reach conclusions and make generalizations about the characteristics of the population.

Focus Group Discussions and key informant questionnaires were transcribed, edited and coded. Each participant comment was simultaneously assigned a separate line on a page as well as each new thought or idea. Each line was labeled with the participant and group number and then entered into Ms Excel Database, compiled and analyzed quantitatively. Tables, graphs and pie charts were used to present results.

\section{Results and Discussion}

In this study, the major impacts of community participation in rural water management were hypothesized to be constant access to adequate water and catchment management through the use of proper farming methods and soil conservation measures. World Bank (2003) argues that the principle impact of a community-driven development approach is expected to be sustained development 
and positive impact on the lives of the poor. Further, Zooneveld (2001) in assessing participation in local governance found that participation worked better when citizen felt that the initiative had concrete aims that were likely to have a direct positive impact on their daily lives. UN-WWAP (2006) also notes that improved governance is essentially about improving people's livelihood opportunities, while providing backbone for governments worldwide to alleviate poverty and increase the chances of sustainable development.

During the study, $56.5 \%$ of the respondents agreed that community participation in rural water management has improved the livelihoods of the local community while $13.5 \%$ disagreed as shown in Figure 2.

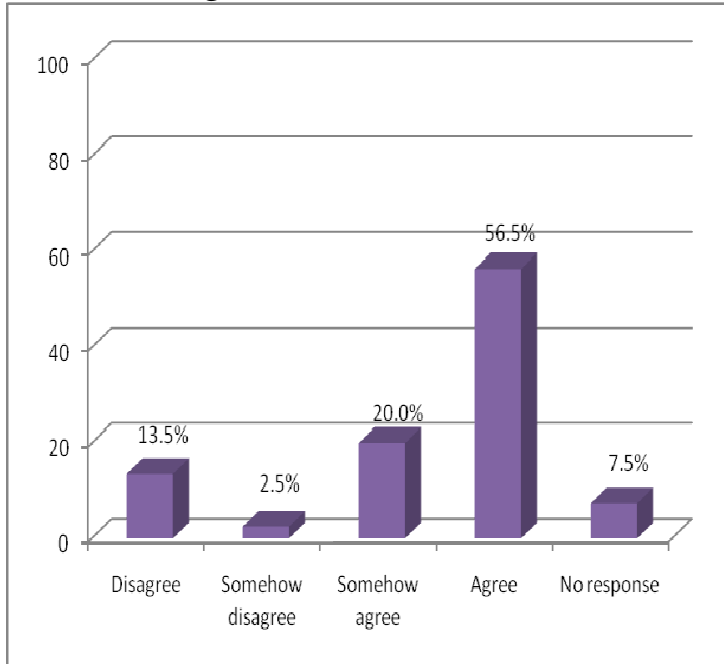

Figure 2 Impact of community participation in rural water management

Thus, on average, community participation in rural water management has made impacts on the livelihoods of the community in the sub-catchment. This study therefore supports World Bank (2003) argument that community participation is seen as a means to achieve a particular end as it enables communities to better manage their socio-economic environment, to improve access to basic social services or to reverse the process of natural resource degradation with the ultimate goal of reducing rural poverty and promoting sustainable development.

Results show that from the total population that agreed that community participation in rural water management has made impact in their livelihoods by providing water for domestic uses (26.4\%), livestock farming $(10.5 \%)$, construction (3.6\%) and crop farming(kitchen gardening) $(0.9 \%)$. In addition, $17.3 \%$ and $10.9 \%$ of the population felt it has led to reduced time wastage when looking for water and general development respectively. However, $5.5 \%$ and $1.8 \%$ of those who disagreed said community participation in rural water management has led to water-use related conflicts and inadequate water supply respectively.

\section{Constant Access to Adequate Water}

Community participation in rural water management is expected to lead to constant access to adequate water for improved livelihoods of the community. The study reveals that $51.4 \%$ of the community felt that their participation has made moderate impact as far as constant access to adequate water is concerned while $27.1 \%$ and $21.5 \%$ felt it has made low and high impact respectively as shown in Figure 3.

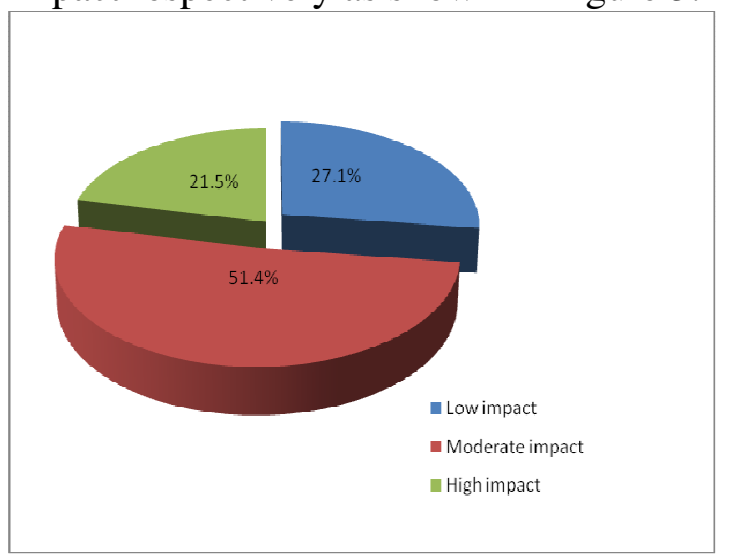

Figure 3 Impact on constant access to adequate water 
Water availability is an essential component in socio-economic development and poverty reduction (UNWWAP, 2006). The study reveals that $51.4 \%$ of the community felt that their participation has made moderate impact as far as constant access to adequate water is concerned while $27.1 \%$ and $21.5 \%$ felt it has made low and high impact respectively as shown in Figure 3. The results show average impact of community participation as far as constant access to adequate water is concerned in the sub-catchment. This contradicts ADB (2007) argument that in order to meet the 2015 Africa Water Vision and Millennium Development Goals (MDGs) target, rural people will need to be provided with access to water. Therefore, in order to avert the negative impacts of inadequate access to water in rural areas, there is a need for more emphasis on community participation in rural water management. This is because water is needed for most productive activities, and inadequate access to water limits the livelihood options of the people, particularly in rural areas (IDRC, 2002).

\section{Catchment Management}

Another impact of community participation on the livelihoods of community in rural water management is catchment management. In this study, catchment management has been looked at in terms of use of proper farming methods and soil conservation measures.

Community participation in rural water management is also expected to have a positive impact as far as catchment management initiative is concerned. According to the Water Act 2002, Water Resource Management Authority should facilitate community participation in catchment management through Water Resource Users Associations in each catchment area. Water users associations have an important role to play in maintaining local water networks as well as mobilizing communities (Brikke, 2004). As CRS (2005) emphasizes, wherever possible, water projects should be incorporated into the existing watershed management plans and should promote multiple uses of water as a means of conserving and using efficiently this scarce resource. Water managers around the world agree that the only way forward to catchment management is through an inclusive and integrated approach to water resource management (UN-WWAP, 2006).

\section{Use of Proper Farming Methods}

During the study $55.2 \%$ of the population felt that community participation has made low impact on the use of proper farming methods as far as catchment management is concerned in the sub-catchment. Meanwhile, $32.6 \%$ and $12.2 \%$ of the population felt that the impact of community participation was moderate and high respectively as shown in Figure 4.

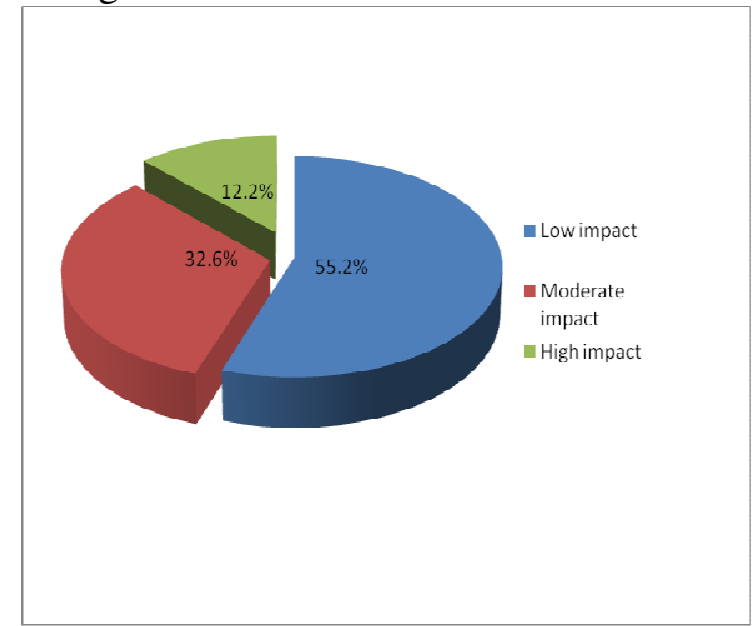

Figure 4 Impact on the use of proper farming methods

These findings indicate that community participation in rural water management in the sub-catchment has made low impacts on catchment management through the use 
of proper farming methods as shown in Plate 1.

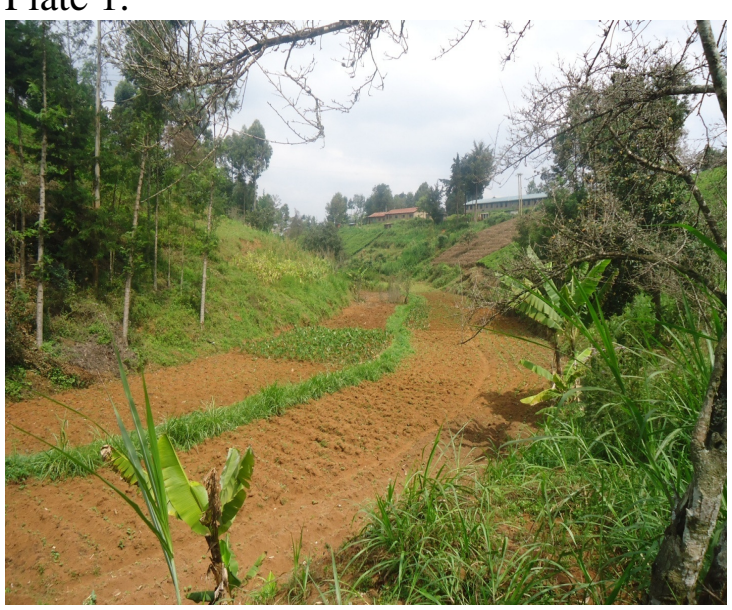

Plate 1: Improper farming methods in the upper section of the sub-catchment

\section{Use of Soil Conservation Measures}

According to the findings of the study, $55.2 \%$ of the population in the subcatchment felt that there is low impact of community participation on the use of soil conservation measures as far as catchment management is concerned. Only $6.1 \%$ of the population felt that there was a high impact as shown in Figure 5.

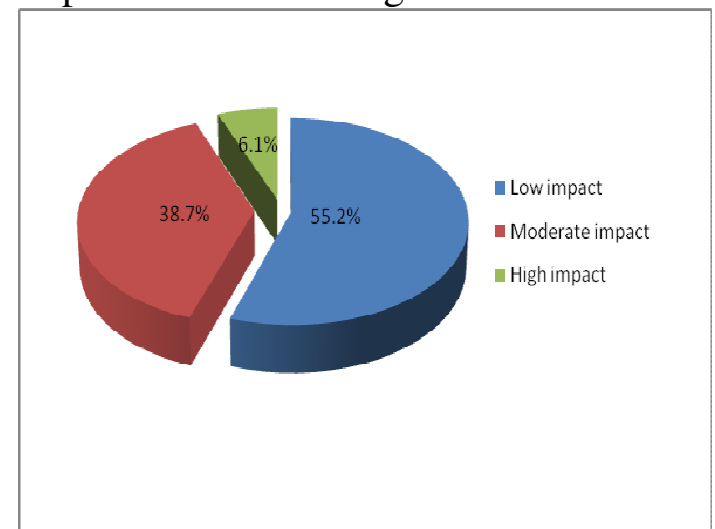

Figure 5 Impact on the use of soil conservation measures

Therefore, community participation in rural water management has made low impact on the use of soil conservation measures in the sub-catchment as shown in Plate 2.

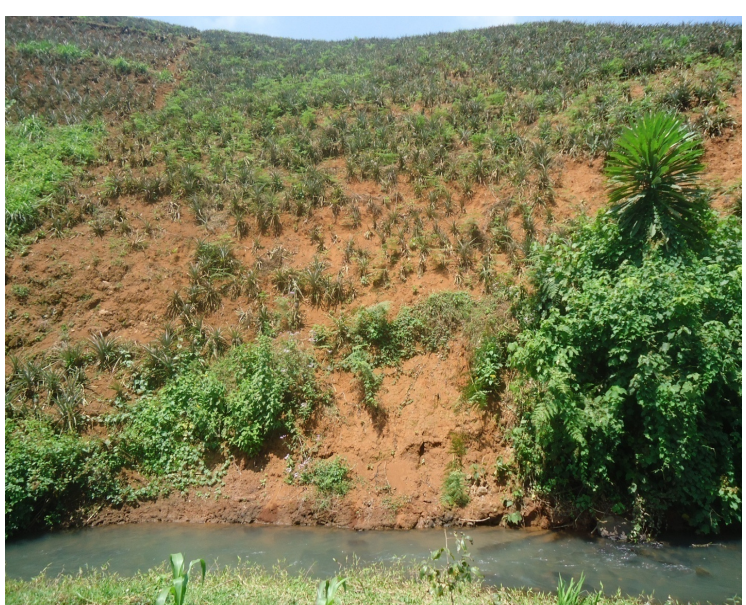

Plate 2: A section of the sub-catchment with poorly protected soil

The research findings also reveal that community participation in rural water management in Ndarugu-Thiririka Subcatchment emphasizes more on constant access to adequate water than catchment management. This contradicts Amerasinghe (2009) findings that improved resource management in catchment areas helps to serve water quality needs and also ensure water availability.

Findings from the study indicate that overemphasis on constant access to adequate water and with little emphasis on catchment management has led to drying up and seasonality of streams which were hitherto perennial as shown in Plate 3.

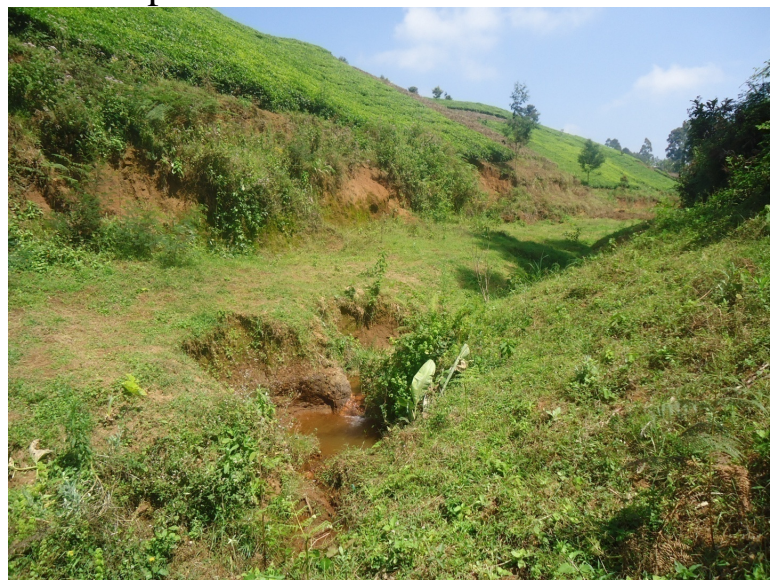

Plate 3: A stream that was perennial now flows during wet seasons only 
Thus, community participation in rural water management should prioritize on catchment management for continued water availability in the right quality and quantity.

\section{Conclusion}

Community participation in the subcatchment has impacted on the livelihood of the local community by providing constant access to adequate water for domestic, agricultural uses, construction, reducing time wastage and general development and also in catchment management. Overall, community participation has made moderate impacts on the livelihoods of the community in the sub-catchment. Furthermore, community participation has made moderate impact on constant access to adequate water and low impact on catchment management based on the use of proper farming methods and soil conservation measures.

\section{Recommendations}

The study recommends the government, Non-Governmental Organizations and donors to provide programmes for intensifying agricultural production, credit and rural financial support and to give adequate and continued financial support to the communities involved in rural water management. Capacity building is also required to enhance the ability of communities in rural water management. This will form the basis for ensuring water availability for rural development.

\section{References}

African Development Bank (2007). Rural Water Supply and Sanitation Intiative: Framework for Implementation: A regional response to Africa's Rural Drinking Water and Sanitation.

Amerasinghe, N.M. (2009). A Study of the Factors Affecting the Sustainability of Community Managed Rural Water Supply Schemes in Sri Lanka. Unpulished Master Thesis, Massachusetts Institute of Technology.

Brikke, F. (2004). Locally, how to involve small-scale enterprises in providing water supply to rural areas, Industry and Environment, vol. 27, No.1, UNEP.

Catholic Relief Services (2005). Guidelines for the development of small-scale rural water supply and sanitation projects in East Africa; A policy and planning framework for activities funded by USAID under Title 11 (Food for Peace) Programme and by other donors; East Africa, Regional office, Nairobi, Kenya.

Chamber, R. (2007). Participation and poverty, Development, Palgrave Macmillan, 50: 20-25.

Garande, T., and Dagg, S. (2005). Public participation and effective water governance at the local level. A case study from small under-developed area in Chile, pp 87-134.

Harvey, P.A., and Reed, R.A. (2007). Community Managed Water Supplies in Africa: Sustainable or Dispensable? Community Development Journal, 2: 66-119.

International Development Research Council (2002). In focus: Water-local level management, IDRC, Canada.

IRC, (2003). Community Water Supply Management: History of a Concept; Delft, the Netherlands, pp 53-116.

Kenya National Bureau of Statistics (2009). 2009 Kenya Population and Housing Census; Volume 1C: 
Population Distribution by age, sex and administrative units.

Kothari, C.R. (2004). Research Methodology: Methods and Techniques, New Age International Publishers, New Delhi, 12-98.

Njogu, J. W. (2009). Challenges and opportunities for sustainable water and demand management in Ruiru municipality; Unpublished Master Thesis, Kenyatta University, Nairobi, Kenya, pp 8-72.

Organization for Economic Development (1985). Management of water projects; Decision making and investment appraisal, Paris, OECD, pp 54-56.

United Nations (2003). Water for people, water for life; World Water Assessment Programme (WWAP); World Water Development Report, Paris, UNESCO and New York, Berghahn Books, pp 89-123.

United Nations (2008). The Millennium Development Goals Report pp 167234.
United Nations Millennium Declaration, (2000). United Nations General Assembly Revolution 2 Session 55, I8th September, 2000, pp 1-9.

The United Nations-World Water Assessment Programme (2006). Water: A shared responsibility; United Nations-World water development report 2; UNESCO, New York.

The Water Act 2002, $24^{\text {th }}$ October, 2002, The Government Printer, Nairobi, Kenya.

World Bank (2003). Community-Driven Development: A study Methodology.

World Health Organization (1996).

Community management of rural water supply and sanitation systemsPoints for Practitioners, Regional Office for Africa, pp 23-88.

Zooneveld, L. (2001). A toolkit for participation in local governance; Learning to make participation work, Novib, 